\title{
AVALIAÇÃO DA ADEQUAÇÃO DAS BOAS PRÁTICAS DE FABRICAÇÃO E QUALIDADE DE CARNE BOVINA EM AÇOUGUES
}

(Evaluation of the adequacy of Good Manufacturing Practices and meat quality in butcher shops)

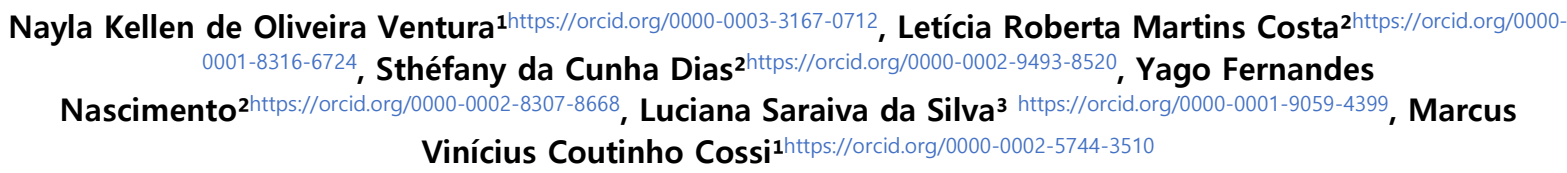

${ }^{1}$ Faculdade de Medicina Veterinária, Universidade Federal de Uberlândia, Faculdade de Medicina Veterinária, Curso de Medicina Veterinária, Uberlândia, Minas Gerais, Brasil; ${ }^{2}$ Programa de Pós Graduação em Saúde Animal, Saúde Pública Veterinária e Segurança Alimentar, Universidade Estadual Paulista Júlio de Mesquita Filho, Faculdade de Medicina Veterinária e Zootecnia, Botucatu, São Paulo, Brasil; ${ }^{3}$ Faculdade de Medicina, Curso de Nutrição, Universidade Federal de Uberlândia, Uberlândia, Minas Gerais, Brasil.

*Corresponding author: marcuscossi@yahoo.com.br

Editora: Julia Arantes Galvão

RESUMO - Este estudo teve como objetivo avaliar a adoção das boas práticas de fabricação e parâmetros físico-químicos ( $\mathrm{pH}$ e temperatura) e microbiológico (presença de Salmonella spp.) da carne moída bovina comercializada em açougues de Uberlândia, MG. Foram analisados 40 estabelecimentos das cinco regiões do município (oito por região), sendo as boas práticas de fabricação avaliadas por meio de um checklist (A. Edificações e Instalações; B. Equipamentos, móveis e utensílios; e C. Manipuladores). Para as análises físico-químicas e microbiológica foram coletadas $200 \mathrm{~g}$ de carne moída bovina. Os estabelecimentos apresentaram 36,5\% de inconformidade quanto à adoção das boas práticas de fabricação, sendo a área externa com focos de insalubridade e a lavagem das mãos os principais problemas observados. Em relação às análises físicoquímicas, identificou-se $75 \%$ de inconformidade dentre os açougues avaliados, sendo constatada também a presença de Salmonella spp. em amostras de carne de dois deles (5\%). Conclui-se que existem falhas na adoção de boas práticas de fabricação e qualidade da carne analisada, e adequações são necessárias para a comercialização de alimentos seguros ao consumidor.

Palavras chave: Higiene dos alimentos; manipulação de alimentos; Salmonella.

ABSTRACT - This study aimed to evaluate the adoption of good manufacturing practices and physico-chemical ( $\mathrm{pH}$ and temperature) and microbiological parameters (presence of Salmonella spp.) of ground beef sold in butcher shops in Uberlândia, MG. Forty establishments from five regions of the city (eight per region) were analyzed, with good manufacturing practices evaluated through a checklist (A. Buildings and Facilities; $B$. Equipment, furniture and utensils; and C. Handlers). For physico-chemical and 
microbiological analysis, $200 \mathrm{~g}$ of ground beef was collected. The establishments presented $36.5 \%$ of nonconformity regarding the adoption of good manufacturing practices, with external area presenting insalubrity spots and hand washing the main observed issues. Regarding the physico-chemical analysis, $75 \%$ of nonconformities were identified among the evaluated butchers, with the presence of Salmonella spp. in meat samples from two of them (5\%). It is concluded that there are flaws in the adoption of good manufacturing practices and the quality of the analyzed meat, and adjustments are necessary in order to commercialize a safe food to the consumer.

Keywords - Food hygiene; food handling; Salmonella.

\section{INTRODUÇÃO}

A carne moída é um alimento fracionado obtido a partir da moagem de massas musculares, seguido de imediato resfriamento ou congelamento (Silva et al., 2015; Oliveira et al., 2018). Esse procedimento provoca excessiva manipulação e maior exposição da área de superfície do produto, o que favorece sua contaminação por microrganismos patogênicos aos humanos como Salmonella spp. e Escherichia coli (Oliveira et al., 2018; Leotta et al., 2016).

Para se produzir um alimento próprio para o consumo, procedimentos como as Boas Práticas de Fabricação (BPF) devem ser implantados ao longo de toda a cadeia produtiva. Neste sentido, a avaliação das condições higiênico-sanitárias de um estabelecimento produtor de alimentos pode ser realizada através da adoção das orientações propostas pela Resolução de Diretoria Colegiada n 275/2002, com a finalidade de identificar conformidades e inconformidades estruturais, de higienização e práticas gerais de manipulação dos alimentos (Brasil, 2002). Assim, é possível traçar ações corretivas, a fim de reduzir os riscos físicos, químicos e biológicos que podem comprometer a saúde do consumidor (Rodrigues et al., 2017; Silveira et al., 2019).

Todos estes cuidados se justificam pelo fato dos açougues serem a última etapa em que se pode mitigar riscos associados à carne, antes que estes cheguem ao consumidor (Barril et al., 2019; Kim et al., 2019; Londero et al., 2019). Porém, apesar de existirem diversas formas diretas e indiretas de avaliar a inocuidade dos alimentos, muitas vezes as ferramentas são utilizadas de forma individualizada. Portanto, o objetivo do presente estudo foi avaliar a adoção das BPF e a qualidade físico-química e microbiológica de carne moída bovina comercializada em estabelecimentos de Uberlândia - MG. 


\section{MATERIAL E MÉTODOS}

A pesquisa foi realizada nos meses de julho a outubro de 2019, em Uberlândia MG. Os estabelecimentos de coleta foram definidos com base no mapa setorial da cidade que divide o município em cinco regiões (norte, sul, leste, oeste e centro). De cada região foram randomicamente selecionados oito bairros, sendo selecionado um açougue de cada bairro $(n=40)$.

Para avaliação das BPF aplicou-se um checklist (Brasil, 2002) com treze itens, divididos nas seguintes categorias: A. Edificação e Instalações (1. área externa livre de focos de insalubridade; 2. área interna livre de objetos em desuso/ estranhos ao ambiente; 3. higienização adequada das instalações; 4. ausência de vetores e pragas urbanas), B. Equipamentos, móveis e utensílios (1. utensílios armazenados em local apropriado; 2. adequada higienização) e C. Manipuladores (1. utilização de uniformes de cor clara; 2. uniformes limpos e em bom estado de conservação; 3. asseio pessoal; 4. lavagem das mãos antes de manipular alimentos ou após qualquer interrupção; 5. manipulação de dinheiro/ quaisquer atitudes que possam contaminar o alimento; 6 . ausência de afecções cutâneas e oculares; 7. presença de avisos com os procedimentos para lavagem das mãos). Os resultados apresentados consideraram a totalidade de estabelecimentos ( $n=40$ ), ou seja, 520 itens avaliados (13 itens em cada estabelecimento e 40 estabelecimentos).

Adicionalmente, para a análise das inconformidades estabeleceu-se que para cada item em inconformidade, o estabelecimento recebeu um ponto, sendo calculada a média de inconformidades para cada categoria do checklist e em cada região analisada do município. A pontuação máxima de inconformidades para Edificações e Instalações, Equipamentos, móveis e utensílios, e Manipuladores foi respectivamente quatro, dois e sete, referentes aos 13 itens avaliados por estabelecimento.

Os dados foram apresentados por meio de tabelas de frequência, medidas de tendência central e de variabilidade. O teste Kolmogorov-Smirnov foi utilizado para avaliar a normalidade da distribuição das variáveis contínuas. Para comparação das inconformidades encontradas nos estabelecimentos dos setores norte, sul, leste, oeste e central de Uberlândia-MG, realizou-se a Análise de Variância (ANOVA) para os dados paramétricos e Kruskal Wallis para dados não paramétricos, com o teste Post-Hoc de Tukey. Para a análise dos dados utilizou-se a significância estatística de $\mathrm{P}<0,05$.

Ainda, no dia em que o estabelecimento foi avaliado quanto as BPF, foi realizada a compra de $200 \mathrm{~g}$ de acém moído (Antunes et al. 2016). Imediatamente após a compra do produto, as amostras foram submetidas à aferição de temperatura por meio de 
termômetro digital de penetração, sendo utilizada a amostra total (200 g) para este procedimento.

Para a determinação do $\mathrm{pH}$, utilizou-se $50 \mathrm{~g}$ de cada amostra homogeneizada com $10 \mathrm{~mL}$ de água destilada, sendo a leitura realizada através do potenciômetro de um pHmetro de bancada previamente calibrado (Brasil, 1981).

A análise microbiológica foi realizada no Laboratório de Inspeção e Tecnologia de Produtos de Origem Animal da Universidade Federal de Uberlândia, onde as amostras foram submetidas ao isolamento de Salmonella spp. segundo metodologia ISO com modificações (ISO, 2017). Deste modo, $25 \mathrm{~g}$ de cada amostra foram pré-enriquecidas em água peptonada tamponada a $1 \%$ seguida do enriquecimento seletivo em Selenito Cistina (SC) e Rappaport Vassiliadis (RV), de acordo com os períodos de incubação e temperaturas recomendados. $\mathrm{O}$ isolamento foi feito em Ágar Xilose Lisina Desoxicolato (XLD) e Ágar Bismuto Sulfito (BS), sendo as colônias típicas submetidas a análises bioquímicas com Ágar Ferro Triplo Açúcar (TSI) e Ágar Lisina Ferro (LIA). As amostras que apresentaram reações típicas foram transferidas e incubadas em caldo Infusão CérebroCoração (BHI) para posterior confirmação por metodologia molecular.

Os isolados suspeitos foram confirmados pela técnica de PCR, tendo como alvo o gene ompC (Dai et al., 2018). Através do método de fervura (Zanetti et al., 2019) extraiuse o DNA, que foi utilizado em reação posterior composta por GoTaq Green Master Mix, água estéril livre de nuclease e primer(i) (ompC-F 5"-ATCGCTGACTTATGCA ATCG-3", ompC-R 5"-CGGGTTGCGTTATAGGTCTG-3").

As condições utilizadas para a reação foram: $96^{\circ} \mathrm{C}$ por 5 minutos para desnaturação inicial, 30 ciclos de $96^{\circ} \mathrm{C}$ por 20 segundos para desnaturação, $58^{\circ} \mathrm{C}$ por 20 segundos para anelamento, $72^{\circ} \mathrm{C}$ por 30 segundos para extensão, e após o término destes 30 ciclos, $72^{\circ} \mathrm{C}$ por 5 minutos para extensão final (Alvarez et al., 2004- adaptado).

Ainda, no Laboratório de Morfologia, Microscopia e Imagem, do Instituto de Biologia da Universidade Federal de Uberlândia, os produtos da PCR foram submetidos à eletroforese horizontal em gel de agarose 1,5\%, posteriormente corados com GelRed e observados em transiluminador (Zanetti et al., 2019- adaptado). Foram utilizados como controle positivo e negativo Salmonella Enteritidis ATCC 13076 e água estéril livre de nuclease, respectivamente. Foram consideradas positivas para Salmonella as amostras com altura de banda respectiva a 204 pares de base. Os resultados foram analisados por frequência de positividade em cada estabelecimento analisado.

Archives of Veterinary Science, v.25, n.4, p. 80-90, 2020. 


\section{RESULTADOS e DISCUSSÃO}

Do total de 520 itens avaliados no checklist foram identificadas 190 inconformidades (36,5\%) distribuídas nos estabelecimentos avaliados em Uberlândia-MG (Tabela 1), sendo a região Norte $(6,25 \pm 1,67)$ e Oeste $(6,00 \pm 2,00)$ as que apresentaram mais inconformidades quando comparadas com o Centro $(3,00 \pm 1,51)(P=0,006)($ Tabela 2). Além disso, a categoria Equipamentos, móveis e utensílios foi aquela que apresentou maior percentual de inconformidades $(56,2 \%)$ em relação às outras categorias avaliadas $(P=0,0002)$.

Tabela 1 - Avaliação das Boas Práticas de Fabricação adotadas nos estabelecimentos $(n=40)$ que comercializam carne moída bovina em Uberlândia-MG.

\begin{tabular}{|c|c|c|c|}
\hline Checklist & & Inconformidades & $\%$ \\
\hline \multirow{5}{*}{$\begin{array}{l}\text { Edificação e } \\
\text { instalações }\end{array}$} & Área externa & 3 & 7,5 \\
\hline & Área interna & 27 & 67,5 \\
\hline & Higienização & 11 & 27,5 \\
\hline & $\begin{array}{l}\text { Ausência de vetores e pragas } \\
\text { urbanas }\end{array}$ & 7 & 17,5 \\
\hline & Total parcial $(n=160)^{1}$ & 48 & $30,0^{a}$ \\
\hline \multirow{3}{*}{$\begin{array}{l}\text { Equipamentos, móveis } \\
\text { e utensílios }\end{array}$} & Utensílios & 26 & 65,0 \\
\hline & Higienização & 19 & 47,5 \\
\hline & Total parcial $(n=80)^{1}$ & 45 & $56,2^{b}$ \\
\hline \multirow{8}{*}{ Manipuladores } & Uniformes & 9 & 22,5 \\
\hline & Uniformes limpos & 3 & 7,5 \\
\hline & Asseio Pessoal & 18 & 45,0 \\
\hline & Lavagem das mãos & 39 & 97,5 \\
\hline & $\begin{array}{l}\text { Atitudes que podem } \\
\text { contaminar o alimento }\end{array}$ & 3 & 7,5 \\
\hline & $\begin{array}{l}\text { Ausência de afecções } \\
\text { cutâneas e oculares }\end{array}$ & 0 & 0 \\
\hline & $\begin{array}{l}\text { Instrução para lavagem das } \\
\text { mãos }\end{array}$ & 25 & 62,5 \\
\hline & Total Parcial $(n=280)^{1}$ & 97 & $34,6^{a}$ \\
\hline \multirow[b]{2}{*}{ Valor de $\mathrm{P}$} & Total $(n=520)$ & 190 & 36,5 \\
\hline & & & $0,0002^{1}$ \\
\hline
\end{tabular}

${ }^{1}$ Frequência de inconformidades comparadas por Kruskal-Wallis.

Nosso estudo apresentou valores de inconformidades semelhantes a outros estudos (26,3\% a 38,3\%) que também avaliaram boas práticas de fabricação em 
estabelecimentos comercializadores de carnes (Rodrigues et al., 2017; Achilles et al., 2017).

Tabela 2 - Comparação das médias de inconformidades na adoção das BPF e da qualidade físico-química de amostras de carne moída bovina comercializadas em estabelecimentos das diferentes regiões de Uberlândia-MG.

\begin{tabular}{|c|c|c|c|c|c|c|}
\hline \multirow{2}{*}{ 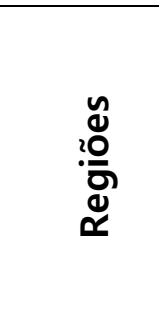 } & \multirow{2}{*}{ 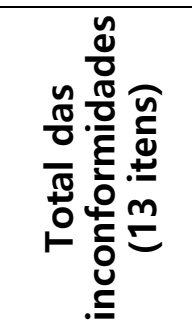 } & \multicolumn{3}{|c|}{ Categorias ${ }^{1}$ avaliadas no Checklist } & \multicolumn{2}{|c|}{$\begin{array}{c}\text { Valor médio das } \\
\text { avaliações físico-química }\end{array}$} \\
\hline & & $\stackrel{A}{\text { (4 itens) }}$ & $\begin{array}{c}\text { B } \\
\text { (2 itens) }\end{array}$ & $\stackrel{C}{\text { (7 itens) }}$ & $\mathrm{pH}$ & Temperatura \\
\hline Norte & $\begin{array}{c}6,25 \\
( \pm 1,67)^{a}\end{array}$ & $\begin{array}{c}1,87 \\
( \pm 0,83)^{a}\end{array}$ & $\begin{array}{c}1,87 \\
( \pm 0,35)^{a}\end{array}$ & $\begin{array}{c}2,50 \\
( \pm 1,19)^{a}\end{array}$ & $\begin{array}{c}5,87 \\
( \pm 0,14)^{a}\end{array}$ & $14,09( \pm 6,43)^{\mathrm{a}}$ \\
\hline Sul & $\begin{array}{c}4,12 \\
( \pm 2,29)^{a, b}\end{array}$ & $\begin{array}{c}1,25 \\
( \pm 1,03)^{a, b}\end{array}$ & $\begin{array}{c}0,75 \\
( \pm 1,03)^{\mathrm{b}}\end{array}$ & $\begin{array}{c}2,12 \\
( \pm 0,99)^{a}\end{array}$ & $\begin{array}{c}5,82 \\
( \pm 0,24)^{a}\end{array}$ & $15,20( \pm 3,73)^{\mathrm{a}}$ \\
\hline Leste & $\begin{array}{c}4,37 \\
( \pm 1,60)^{\mathrm{a}, \mathrm{b}}\end{array}$ & $\begin{array}{c}1,12 \\
( \pm 0,35)^{a, b}\end{array}$ & $\begin{array}{c}0,75 \\
( \pm 0,89)^{\mathrm{b}}\end{array}$ & $\begin{array}{c}2,50 \\
( \pm 0,92)^{a}\end{array}$ & $\begin{array}{c}5,85 \\
( \pm 0,24)^{a}\end{array}$ & $12,51( \pm 4,39)^{a}$ \\
\hline Oeste & $\begin{array}{c}6,00 \\
( \pm 2,00)^{a}\end{array}$ & $\begin{array}{c}1,50 \\
( \pm 0,92)^{a}\end{array}$ & $\begin{array}{c}1,87 \\
( \pm 0,35)^{a}\end{array}$ & $\begin{array}{c}2,62 \\
( \pm 0,92)^{a}\end{array}$ & $\begin{array}{c}5,72 \\
( \pm 0,15)^{a}\end{array}$ & $17,96( \pm 4,55)^{\mathrm{a}}$ \\
\hline Centro & $\begin{array}{c}3,00 \\
( \pm 1,51)^{b}\end{array}$ & $\begin{array}{c}0,25 \\
( \pm 0,46)^{b}\end{array}$ & $\begin{array}{c}0,37 \\
( \pm 0,52)^{\mathrm{b}}\end{array}$ & $\begin{array}{c}2,37 \\
( \pm 1,30)^{a}\end{array}$ & $\begin{array}{c}5,89 \\
( \pm 0,19)^{a}\end{array}$ & $14,00( \pm 6,73)^{a}$ \\
\hline $\begin{array}{l}\text { Valor } \\
\text { de P }\end{array}$ & $0,006^{3}$ & $0,006^{2}$ & $0,001^{2}$ & $0,822^{2}$ & $0,156^{2}$ & $0,339^{3}$ \\
\hline
\end{tabular}

${ }^{1}$ A. Edificação e Instalações; B. Equipamentos, móveis e utensíliosi C. Manipuladores; ${ }^{2}$ Kruskall Wallis; ${ }^{3}$ ANOVA.

Ao considerar os 160 itens avaliados em Edificação e Instalações, foram identificadas 48 inconformidades (30\%) (Tabela 1). Nota-se que as regiões Norte $(1,87 \pm$ $0,83)$ e Oeste $(1,50 \pm 0,92)$ apresentaram mais inconformidades quando comparadas ao Centro $(0,25 \pm 0,46)(P=0,006)$ (Tabela 2). $O$ item "área interna livre de objetos em desuso ou estranhos ao ambiente" apresentou 67,5\% de inconformidade, sendo observado a presença de celulares, ventiladores e materiais de limpeza.

Do total de 80 itens avaliados na categoria Equipamentos, móveis e utensílios foram identificadas 45 inconformidades (56,2\%) (Tabela 1). Observa-se que as regiões Norte e Oeste apresentaram mais inconformidades quando comparadas as regiões Sul, Leste e Centro $(P=0,001)$ (Tabela 2). Nesta categoria, foi observado inconformidades no item "utensílios armazenados em local apropriado" em 65\% (26/40) dos açougues avaliados. Além disso, 47,5\% (19/40) apresentavam seus utensílios mal higienizados, sendo possível observar a presença de vetores à sua volta. 
As inconformidades observadas em Edificação e instalações, e Equipamentos, móveis e utensílios representam possíveis fontes de contaminação cruzada, pois dificultam o processo de higienização, contribuindo para a contaminação do alimento comercializado (Leotta et al., 2016). Além disso, a má higienização da superfície possibilita a formação de biofilmes, o que potencializa os riscos à saúde humana (Londero et al., 2019)

Em relação à categoria Manipuladores, observou-se que $34,6 \%$ dos itens apresentaram inconformidades não havendo diferença entre as regiões $(P=0,822)$ (Tabela 1 e 2). O item menos observado nas visitas foi "lavagem das mãos antes de manipular alimentos ou após qualquer interrupção" que apresentou 97,5\% de inconformidade. Além disso, dentre todos os manipuladores avaliados, 22,5\% (9/40) não utilizavam uniformes de cor clara e 45\% (18/40) não se apresentavam barbeados ou com o cabelo protegido, além de utilizarem adornos, como relógios, anéis e pulseiras, enquanto manipulavam o alimento.

O asseio pessoal insuficiente por parte dos manipuladores pode contribuir para a contaminação do produto e ocorrência de doenças de origem alimentar (Reynolds; Dolasinski 2019). Neste sentido, é importante que treinamentos sejam realizados para auxiliar a adoção de hábitos higiênicos e melhoria destes estabelecimentos (Leotta et al., 2016).

Já em relação às análises físico-químicas, observou-se que não houve diferença estatística entre as regiões quanto a temperatura $(P=0,339)$ e ao $\mathrm{pH}(P=0,156)$ (Tabela 2). Nota-se que ao considerar o padrão estabelecido pela Instrução Normativa $n^{\circ} 83$ de 2003, apenas cinco amostras (12,5\%) seriam classificadas como adequadas para comercialização por apresentarem temperatura inferior a $7^{\circ} \mathrm{C}$ (Brasil, 2003). A temperatura mais alta mensurada $\left(25,5^{\circ} \mathrm{C}\right)$ foi em uma amostra de carne obtida no Centro, região bem avaliada pelos critérios abordados no checklist de BPF.

Valores de temperatura acima do recomendado indicam falha dos estabelecimentos em monitorar este parâmetro, essencial para o controle do crescimento microbiano. Bonacina et al. (2017) também identificaram problema similar e o maior valor encontrado foi de $9,48^{\circ} \mathrm{C}$. Isto é preocupante, pois os principais deteriorantes de carne e patógenos de origem alimentar são capazes de crescer em temperaturas que variam de 6,7 a $47,8^{\circ} \mathrm{C}$ (Jay, 2005).

Já em relação ao pH, a legislação nacional considerava que apenas carnes bovinas in natura com pH de 5,8 a 6,2 seriam consideradas "boas para o consumo" e sendo assim, 25 amostras (62,5\%) analisadas no presente estudo estavam com valor de $\mathrm{pH}$ 
inferior a este limite (Brasil, 1981). Entretanto, em 2018 houve a revogação da portaria que apresentava estes valores para promulgação de novas metodologias de análise e não há até o momento limites legais previstos para pH (Brasil, 2018).

O menor valor de $\mathrm{pH}$ mensurado neste trabalho foi 5,51, e foi obtido em uma amostra adquirida na região Oeste, setor do município que, juntamente com a região Norte, localizavam os estabelecimentos com maior número de inconformidades. Valores de $\mathrm{pH}$ abaixo de 5,8 indicam a presença de microrganismos deteriorantes que ao se proliferarem produzem compostos ácidos, o que provoca a queda do $\mathrm{pH}$ do meio (Silva et al., 2018). Este é um parâmetro muito variável entre os estudos sendo por vezes observada $100 \%$ de adequação do $\mathrm{pH}$ e em outros $75 \%$ das amostras com valores inadequados (Costa; Tanamati, 2018; Bonacina et al., 2017).

Neste trabalho, identificou-se a presença de Salmonella spp. em amostras de dois estabelecimentos (5\%), ambos da região Norte. Salmonella é uma bactéria frequentemente associada a surtos de origem alimentar e portanto, sua presença no alimento é um risco à saúde do consumidor, além de uma inconformidade em relação à legislação vigente (Thomas et al., 2020; Brasil, 2019). Sabe-se, entretanto, que somente a ausência de Salmonella não garante que a carne seja inócua, já que muitas outras bactérias podem estar envolvidas em surtos de toxinfecções alimentares (Fegan; Jeson, 2018).

Destaca-se que embora $\mathrm{o} \mathrm{pH}$ e temperatura da maioria das amostras esteja inaceitável, a qualidade da carne não é o resultado da atuação isolada destas duas variáveis, pois sofre também influência de todas as BPF adotadas no estabelecimento (Antunes et al., 2016). Fato observado nas duas amostras positivas para Salmonella spp. que, apesar de estarem adequadas quanto ao $\mathrm{pH}(5,81$ e 5,82) e temperatura $(4,6$ e 4,3), foram obtidas em estabelecimentos com falhas nas BPF. Ambos os estabelecimentos apresentavam presença de objetos estranhos ao ambiente, presença de vetores, utensílios armazenados em local desapropriado, má higienização dos equipamentos e utensílios; além de funcionários que não lavaram as mãos antes da manipulação do alimento.

Estas observações reforçam a importância da análise conjunta de fatores que podem alterar a qualidade do alimento (Yu et al., 2019), para assim realizar uma correta avaliação de sua inocuidade. A adequada avaliação por sua vez, permitirá o planejamento de ações corretivas, o que contribuirá para a redução de inadequações e melhoria da qualidade do produto comercializado (Silva et al., 2015).

Por fim, embora tenham sido identificadas variações na adoção de BPF nos estabelecimentos das diferentes regiões analisadas, novos trabalhos são necessários para 
investigar as possíveis explicações para este resultado. A natureza exploratória deste estudo e o fato do checklist previsto na legislação ter sido adotado de forma parcial e aplicado de maneira oculta, impossibilitaram a obtenção desta resposta. Novos estudos devem considerar aspectos que podem influenciar os itens avaliados, como: nível socioeconômico dos estabelecimentos e da região ao seu entorno; frequência de fiscalização pelos órgãos competentes; e nível de instrução dos manipuladores (Silva et al., 2015; Rodrigues et al., 2017; Achilles et al., 2017).

\section{CONCLUSÃO}

Existem falhas na adoção das BPF nos açougues avaliados e inadequações quanto às análises físico-químicas e microbiológica da carne moída bovina comercializada, o que representa um risco a saúde dos consumidores.

\section{Agradecimento}

Ao Programa de Educação Tutorial (PET) Medicina Veterinária e ao Núcleo de Estudos em Saúde Pública e Produtos de Origem Animal (NESPOA), da Universidade Federal de Uberlândia - UFU.

\section{REFERÊNCIAS}

ACHILLES, R.R.; NESPOLO, C.R.; BRASIL, C.C.B. et al. Condições higiênicas em açougues de Itaqui, Rio Grande do Sul. Revista de Nutrição e Vigilância em Saúde, v.4, n.1, p.21-31, 2017.

ALVAREZ, J.; SOTA, M.; VIVANCO, A.B. et al. Development of a multiplex PCR technique for detection and epidemiological typing of Salmonella in human clinical samples. Journal of Clinical Microbiology, v.42, n.4, p.1734-1738, 2004

ANTUNES, A.R.; OLIVEIRA, G.L.; SALEMA, R.B. et al. Pesquisa de coliformes em carne bovina comercializada no município do Vale do Jequitinhonha MG. Higiene Alimentar, v.30, n.256/257, p.82-86, 2016.

BARRIL, P.A.; SOTO, S.A.; JAUREGUIBERRY, M.V. et al. Microbiological risk characterization in butcher shops from the province of Neuquen, Patagonia Argentina. LWT - Food Science Technology, v.107, p.35-40, 2019.

BRASIL. Ministério da Agricultura, Pecuária e Abastecimento. Portaria nº1, de 07 de outubro de 1981. Métodos Analíticos Oficiais para Controle de Produtos de Origem Animal e seus Ingredientes: métodos físicos e químicos. Brasília: Diário Oficial da União, Brasília, 1981. 
BRASIL. Agência Nacional de Vigilância Sanitária. Resolução RDC n ²75, de 21 de outubro de 2002. Dispõe sobre o regulamento técnico de procedimentos operacionais padronizados aplicados aos estabelecimentos produtores/ industrializadores de alimentos e a lista de verificação das boas práticas de fabricação em estabelecimentos produtores/industrializadores de alimentos. Brasília: Diário Oficial da União, 2002.

BRASIL. Ministério da Agricultura Pecuária e Abastecimento. Instrução Normativa $n^{\circ} 83$, de 21 de novembro de 2003. Aprova os regulamentos técnicos de identidade e qualidade de carne bovina em conserva e carne moída de bovino. Brasília: Diário Oficial da União, 2003.

BRASIL. Ministério da Agricultura Pecuária e Abastecimento. Instrução Normativa $\mathrm{n}^{\circ} 30$, de 26 de junho de 2018. Estabelece como oficiais os métodos constantes do Manual de Métodos Oficiais para Análise de Alimentos de Origem Animal, indexado ao International Standard Book Number (ISBN) sob o número 978-85-7991-111-8. Brasília: Diário Oficial da União, 2018.

BRASIL. Agência Nacional de Vigilância Sanitária. Instrução Normativa $n^{\circ}$ 60, de 23 de dezembro de 2019. Estabelece as listas de padrões microbiológicos para alimentos. Brasília: Diário Oficial da União, 2019.

BONACINA, M.S.; BACCIN, M.A.; ROSA, L.S. Avaliação de parâmetros indicativos da qualidade da carne bovina moída comercializada em diferentes supermercados em Erechim, Rio Grande do Sul. Vigilância Sanitária em Debate: Sociedade, Ciência \& Tecnologia, v.5, n.4, p.9-16, 2017.

COSTA, L.C.; TANAMATI, A. Avaliação higiênico-sanitária e físico-química de carne in natura comercializada em Campo Mourão-PR. Revista Uningá Review, v.33, n.1, p.55-65, 2018.

DAI, X.; LIU, M.; PAN, K. et al. Surface display of OmpC of Salmonella serovar Pullorum on Bacillus subtilis spores. PLOS ONE, v.13, n.1, p.1-11, 2018.

FEGAN, N.; JENSON, I. The role of meat in foodborne disease: Is there a coming revolution in risk assessment and management? Meat Science, v.144, p.22-29, 2018. INTERNATIONAL ORGANIZATION FOR STANDARDIZATION - ISO. ISO 6579. Microbiology of food chain: Horizontal method for the detection, enumeration and serotyping of Salmonella spp.- Part 1: detection of Salmonella spp. Geneva, 2017.

JAY, J.M. Microbiologia de alimentos. Porto Alegre: Artmed, 2005. 712 p.

KIM, H.E.; LEE, J.J.; LEE, M.J. et al. Analysis of microbiome in raw chicken meat from butcher shops and packaged products in South Korea to detect the potential risk of foodborne illness. Food Research International, v.122, p.517-527, 2019. 
LEOTTA, G.A.; BRUSA, V.; GALLI, L. et al. Comprehensive evaluation and implementation of improvement actions in butcher shops. PLOS ONE, v.11, n.9, p.1-16, 2016.

LONDERO, A.; COSTA, M.; GALLI, L. et al. Characterization and subtyping of Listeria monocytogenes strains from butcher shops. LWT - Food Science and Technology, v.113, p.1-6, 2019.

OLIVEIRA, A.C.S.; PEDROSO, S.C.S.; CARDILLI, D.J. et al. Brazilian ground beef authentication by multiplex polymerase chain reaction. Ciência Rural, v.48, n.2, p.1-7, 2018.

REYNOLDS, J.; DOLASINSKI, M.J. Systematic review of industry food safety training topics \& modalities. Food Control, v.105, n.1-7, 2019.

RODRIGUES, A.A.; SOUSA, W.L.; PINHEIRO, R.E.E. et al. Aspectos higiênico-sanitários de estabelecimentos comercializadores de carnes no município de Bom Jesus-PI. Revista Brasileira de Higiene e Sanidade Animal, v.11, n.1, p.94-103, 2017.

SILVA, A.P.R.; LONGHI, D.A.; DALCANTON, F. et al. Modelling the growth of lactic acid bacteria at different temperatures. Brazilian Archives of Biology and Technology, v.61, 2018.

SILVA, R.R.L.; GOUVEIA, D.S.; ROCHA, A.P.T. et al. Análise de coliformes e verificação das Boas Práticas de Fabricação de carne moída comercializada na cidade de Campina Grande-PB. Revista Verde de Agroecologia e Desenvolvimento Sustentável, v.10, n.1, p.115-119, 2015.

SILVEIRA, D.R.; KAEFER, K.; PORTO, R.C. et al. Qualidade microbiológica de produtos de origem animal encaminhados para alimentação escolar. Ciência Animal Brasileira, v.20, p.1-8, 2019.

THOMAS, K.M.; GLANVILLE, W.A.; BARKER, G.C. et al. Prevalence of Campylobacter and Salmonella in African food animals and meat: A systematic review and metaanalysis. International Journal of Food Microbiology, v.315, p.1-22, 2020.

YU, J.; YANG, H.M.; WAN, X.L. et al. Effects of cottonseed meal on slaughter performance, meat quality, and meat chemical composition in Jiangnan White goslings. Poultry Science, v.99, n.1, p.207-213, 2019.

ZANETTI, N.S.; DE CARLI, S.; SOUZA, M.N. et al. Molecular detection and characterization of Salmonella Gallinarum from poultry farms in Brazil. The Journal of Applied Poultry Research, v.28, n.4, p.335-1341, 2019. 